SAND2010-1910

Unlimited Release

Printed March 2010

\title{
Economic and Policy Implications of Pandemic Influenza
}

\section{AUTHORS}

Verne W. Loose, Vanessa N. Vargas, Drake E. Warren, Shirley J. Starks, and Theresa J. Brown, Braeton J. Smith

Prepared by

Sandia National Laboratories

Albuquerque, New Mexico 87185

Sandia National Laboratories is a multi-program laboratory operated by Sandia Corporation, a wholly owned subsidiary of Lockheed Martin company, for the U.S. Department of Energy's National Nuclear Security Administration under contract DE-AC04-94AL85000.

\section{Sandia National Laboratories}


Issued by Sandia National Laboratories, operated for the United States Department of Energy by Sandia Corporation.

NOTICE: This report was prepared as an account of work sponsored by an agency of the United States Government. Neither the United States Government, nor any agency thereof, nor any of their employees, nor any of their contractors, subcontractors, or their employees, make any warranty, express or implied, or assume any legal liability or responsibility for the accuracy, completeness, or usefulness of any information, apparatus, product, or process disclosed, or represent that its use would not infringe privately owned rights. Reference herein to any specific commercial product, process, or service by trade name, trademark, manufacturer, or otherwise, does not necessarily constitute or imply its endorsement, recommendation, or favoring by the United States Government, any agency thereof, or any of their contractors or subcontractors. The views and opinions expressed herein do not necessarily state or reflect those of the United States Government, any agency thereof, or any of their contractors.

Printed in the United States of America. This report has been reproduced directly from the best available copy.

Available to DOE and DOE contractors from

U.S. Department of Energy

Office of Scientific and Technical Information

P.O. Box 62

Oak Ridge, TN 37831

Telephone: (865)576-8401

Facsimile: (865)576-5728

E-Mail: reports@adonis.osti.gov

Online ordering: http://www.osti.gov/bridge

Available to the public from

U.S. Department of Commerce

National Technical Information Service

5285 Port Royal Rd

Springfield, VA 22161

Telephone: (800)553-6847

Facsimile: (703)605-6900

E-Mail: orders@ntis.fedworld.gov

Online order: http://www.ntis.gov/help/ordermethods.asp?loc=7-4-0\#online

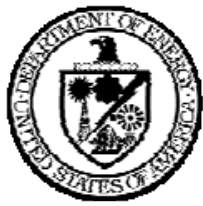


SAND 2010-1910

Unlimited Release

Printed March 2010

\title{
Economic and Policy Implications of Pandemic Influenza
}

\author{
Verne W. Loose and Vanessa N. Vargas \\ Computational Economics Group \\ Drake E. Warren \\ Systems Analysis and Operations Research Group \\ Shirley J. Starks \\ Systems Research and Applications Group \\ Theresa J. Brown \\ Program Manager, Infrastructure and Economic Systems Analysis Group \\ Braeton J. Smith \\ Computational Economics Group \\ Sandia National Laboratories \\ P.O. Box 5800 \\ Albuquerque, New Mexico 87185-1138
}

\begin{abstract}
Pandemic influenza has become a serious global health concern; in response, governments around the world have allocated increasing funds to containment of public health threats from this disease. Pandemic influenza is also recognized to have serious economic implications, causing illness and absence that reduces worker productivity and economic output and, through mortality, robs nations of their most valuable assets-human resources. This paper reports two studies that investigate both the short- and long-term economic implications of a pandemic flu outbreak. Policy makers can use the growing number of economic impact estimates to decide how much to spend to combat the pandemic influenza outbreaks.
\end{abstract}




\section{Acknowledgments}

The authors gratefully acknowledge the financial support of the U.S. Department of Homeland Security (DHS), Office of Infrastructure Protection (IP), Risk Development and Modeling Branch (RDMB), Branch Chief Dean Checknita; and the National Bio-Surveillance Integration Center (NBIC), Director Eric Myers, all of whom also provided the policy impetus to the investigation of these questions. The authors are grateful to the many staff members of National Infrastructure Simulation and Analysis Center (NISAC) at both Sandia National Laboratories (SNL) and Los Alamos National Laboratory (LANL) who provided the intellectual stimulus wherein this work could flourish. We are grateful to LANL for the detailed epidemiological calculations which were a significant component of this analysis. Very able research assistance by Calvin R. Shaneyfelt is greatly appreciated. Finally, editors at SNL were invaluable in ensuring that descriptions of the analysis were clear, crisp, and accurate. We are indebted to them but do not hold them responsible for any errors, misconceptions, or omissions. Those are the responsibility solely of the authors. 


\section{Table of Contents}

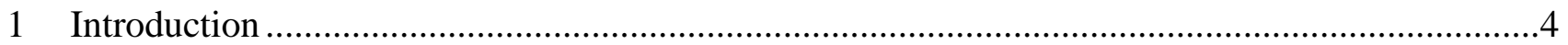

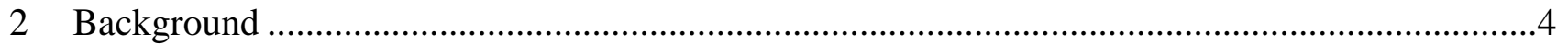

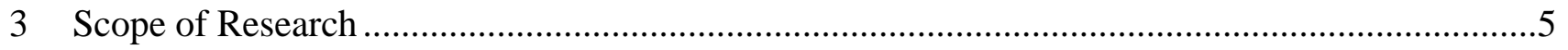

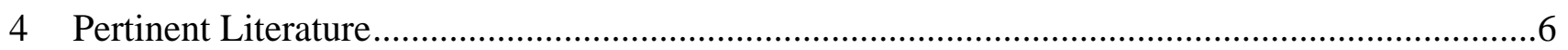

5 Pre-Modeling to Prepare the Forecasting Model ........................................................................

5.1 Description of the Regional Economics Models, Inc...........................................................

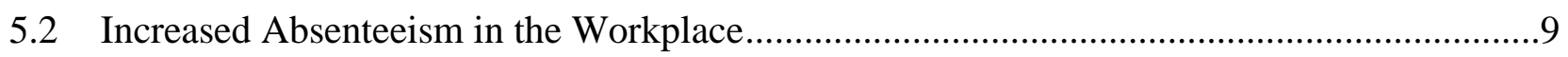

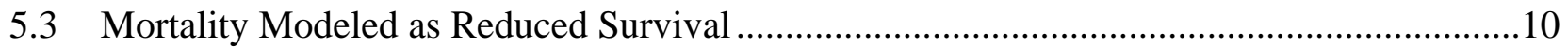

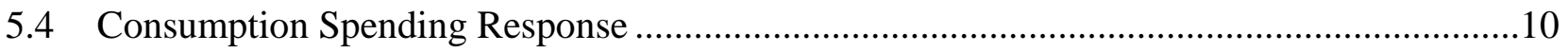

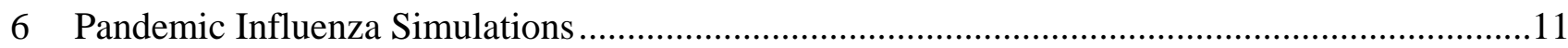

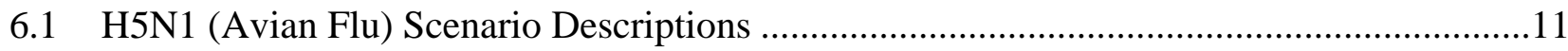

6.1.1 Important Scenario Parameters, Assumptions .................................................................12

6.1.2 Simulation Results .............................................................................................12

6.1.3 Discussion of Simulation Results ............................................................................13

6.2 H1N1 (Swine Flu) Scenarios...........................................................................................16

6.2.1 Important Scenario Parameters, Assumptions ............................................................16

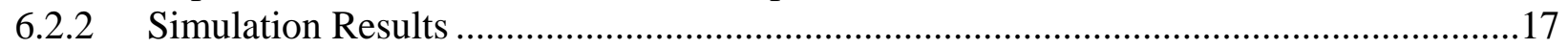

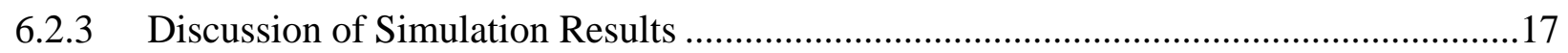

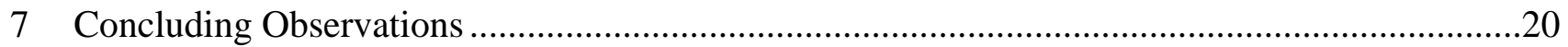

\section{Figures}

Figure 5-1: Major REMI Economic Variable Categories and Relationships ........................................8 Figure 5-2: Economic Impacts are Measured as Difference between Impact and Baseline Forecasts.9 Figure 6-1: Average Gross Domestic Product Losses, by Type of Shock and Industry: Year 1, Baseline Scenario ………..............................................................................................

Figure 6-2: Percent Changes in Gross Domestic Product by State: Baseline Scenario, Year 1 ..........15

Figure 6-3: Factor Analysis for Selected Industry Sectors ................................................................18

Figure 6-4: Percentage Gross Domestic Product Reductions for Three Scenarios ..............................19

\section{Tables}

Table 4-1: Previous Pandemic Influenza Economic Impact Studies ....................................................

Table 6-1: Key Epidemiological Parameters ...............................................................................12

Table 6-2: Estimated National Gross Domestic Product Reductions ....................................................13

Table 6-3: Estimated National Gross Domestic Product Reductions .....................................................17 
Acronyms, Abbreviations and Initialisms

\begin{tabular}{|l|l|}
\hline \multicolumn{1}{|c|}{ Acronym } & \multicolumn{1}{c|}{ Definition } \\
\hline Avian Flu & H5N1 Influenza \\
\hline CMG & Community Mitigation Guidance \\
\hline CMG-SE & Community Mitigation Guidance-Selected Elements \\
\hline DHS & U.S. Department of Homeland Security \\
\hline EpiSimS & Epidemic Simulation System \\
\hline GDP & Gross Domestic Product \\
\hline LANL & Los Alamos National Laboratory \\
\hline LAUR & Los Alamos Unlimited Release \\
\hline NAICS & North American Industry Classification System \\
\hline NBIC & National Bio-Surveillance Integration Center \\
\hline NISAC & National Infrastructure Simulation and Analysis Center \\
\hline SARS & Severe Acute Respiratory Syndrome \\
\hline Swine Flu & H1N1 Influenza \\
\hline REMI & Regional Economic Modeling, Inc. \\
\hline
\end{tabular}

\section{Introduction}

Experts recognize that pandemic influenza has serious global economic implications. The illness causes absenteeism, reduced worker productivity, and therefore reduced economic output. This, combined with the associated mortality rate, robs nations of valuable human resources. Policy makers can use economic impact estimates to decide how much to spend to combat the pandemic influenza outbreaks.

In this paper economists examine two studies which investigate both the short- and long-term economic implications of a pandemic influenza outbreak. Resulting policy implications are also discussed. The research uses the Regional Economic Modeling, Inc. (REMI) Policy Insight + Model. ${ }^{1}$ This model provides a dynamic, regional, North America Industrial Classification System (NAICS) industry-structured framework for forecasting. It is supported by a population dynamics model that is well-adapted to investigating macro-economic implications of pandemic influenza, including possible demand side effects. The studies reported in this paper exercise all of these capabilities.

\section{Background}

Influenza is a recurring, seasonal phenomenon, usually of the winter months, that has three major economic implications.

People who become ill either stay home to recover, or they go to work, school, or other social engagements while ill-- possibly exposing and infecting other people. When ill employees stay home, their absence results in lower workplace productivity and a consequent reduction in economic output that can be referred to as the supply side effect.

\footnotetext{
${ }^{1}$ For a more detailed description of the REMI model, see the resources available at REMI's website (www.remi.com), including: Treyz, George I., Dan S. Rickman, and Gang Shao, 1991, “The REMI Economic-Demographic Forecasting and Simulation Model,” International Regional Science Review, 14(3), pp. 221-253
} 
Partly due to the advance of global interconnectedness in recent decades, influenza strains have spread more rapidly among populations, leading to worldwide infection. Sometimes these strains are very virulent and have the potential to cause a great deal of illness and death. Media reporting of such global phenomena has the potential to cause a demand side response among consumers. This is a panic response among people who then avoid places of social congregation - school, public transportation, eating and entertainment establishments, and so forth The associated decrease in consumption results in a demand side effect.

Some people, particularly those who are already health compromised, succumb to the disease and die; this constitutes both a supply and a demand side effect - they are no longer producing or consuming goods and services.

These globally circulating flu strains are sometimes overlaid on the seasonal flu. When that happens two or more strains can circulate simultaneously, either independently or they may interact with each other. ${ }^{2}$ Seasonal flu has become an expected, widely publicized fall and winter phenomenon in North America. Consequently, the likelihood of output reduction caused by worker absenteeism is generally accepted, even anticipated. The demand side effect, in which people are thought to curtail expenditures out of fear of exposure to infection or uncertainty about their futures is perhaps less well-established and certainly less well understood.

\section{Scope of Research}

One of the main concerns of a pandemic influenza outbreak is the effect it will have on people's daily lives, including their productive life at the office, factory, home, school, or other social or economic setting. In response, governments around the world have allocated increasing funds to combat the negative public health effects, especially mortality (individuals with compromised health who contract the flu are at highest risk to suffer mortality). However, government policy actions can also have economic consequences. So policy makers need information on predictable consequences of the different government initiatives.

Officials need to be able to determine which will be worse economically: their attempted intervention or the disease itself. Economists carried out two studies to address some of these issues. One study is related to a hypothetical outbreak of avian influenza — the H5N1 influenza — while the other is directed to the evolving H1N1 influenza outbreak of 2009 and 2010. The two studies share a common analytical approach and, accordingly, results for the two are reported together.

The process and results of modeling the first-year and long-term economic effects of two pandemic influenza scenarios are explained in this paper. Economists pattern one scenario after the H5N1 (the so-called Avian Influenza) of 2008 and the other scenario reflects the characteristics of the H1N1 (the so-called Swine Flu) influenza of 2009-2010. The same models are used to investigate both scenarios; one remaining difference in the two studies is the shorter time frame of the H5N1 study, with estimates of 10-year impact while the H1N1 Influenza study analysis was carried out to 2050.

\footnotetext{
${ }^{2}$ Bio-medical technology has advanced to the point that in recent times (last several decades) the potential exists to identify the globally circulating flu strains and even to identify their country of origin.
} 


\section{Pertinent Literature}

Studies investigating the macro-economic implications of global public health phenomena such as pandemic influenza have proliferated in the last several decades. The Severe Acute Respiratory Syndrome (SARS) outbreak in Asia caused economic disruption even though a global health crisis was avoided. Lee and McKibbin (2003) used a global model to estimate impacts of SARS disruption on Asian countries and concluded that GDP reductions ranged between negative 0.5 percent and negative 0.263 percent for China, Hong Kong, Singapore and Taiwan. Analysis of the data revealed that the retail-service sector and travel industries suffered the largest declines in business and income. Siu and Wong (2004) reported that retail sales figures dropped 15.2 percent between late 2002 and April 2003. They also reported substantial declines in passenger travel to Hong Kong of 10.4 percent over a similar time period. Fan (2003) studied the impact of SARS and concluded that the main economic impact of SARS was on the demand side, as consumption and the demand for services contracted. Bloom et al. (2005), who performed a study for the Asian Development Bank, used Fan's estimates in his model. These data analyses provide evidence that consumers do curtail consumption, at least temporarily, in the face of increased public health uncertainty.

Studies by The Brookings Institution (McKibbin 2006), and the Congressional Budget Office (2005, revised 2006), evinced more complete modeling and analysis of the effects of pandemics for the United States. Studies conducted for other areas of the world include those by Kennedy, Thompson and Vujanovic (2006), who conducted a study of the impact of pandemic influenza in Australia; James and Sargent (2006), who conducted a study of the impact on Canada; Jonung and Kroger (2006), who estimated the impact on Europe; Douglas, Szeto and Buckle (2006), who estimated the impact on New Zealand; and the Bank of Montreal, which performed a study of the global impact. The main findings of these papers are summarized in Table 4-1.

More recent studies by Sadique (2008) and Lempel (2009) examine the cost of public health interventions in the form of school closures as a means to mitigate the effects of a rapidly spreading pandemic influenza. These two studies strongly suggest the importance of economic analyses that weigh the cost of such measures (possibility of increased absenteeism) against their benefits, presumably in terms of reduced morbidity and mortality rates from the pandemic. 
Table 4-1: Previous Pandemic Influenza Economic Impact Studies

\begin{tabular}{|l|l|c|c|}
\hline \multicolumn{1}{|c|}{ Pandemic Influenza Economic Studies } & \multicolumn{2}{c|}{ Scope } & \multicolumn{2}{c|}{$\begin{array}{c}\text { First year Gross } \\
\text { Domestic } \\
\text { Product Impact }\end{array}$} \\
\cline { 2 - 4 } Bloom, et al. (Asian Development Bank) & \multicolumn{1}{|c|}{$\begin{array}{c}\text { High } \\
\text { (excluding Japan) }\end{array}$} & $2.60 \%$ & $6.80 \%$ \\
\hline McKibbin (Brookings Institution) & US & $0.60 \%$ & $5.50 \%$ \\
\hline Nesbitt, Burns (Bank of Montreal) & Global & $2.0 \%$ & $6.0 \%$ \\
\hline Congressional Budget Office & US & $1.0 \%$ & $4.25 \%$ \\
\hline Douglas, Szeto and Buckle (New Zealand Treasury) & New Zealand & $5.0 \%$ & $10.0 \%$ \\
\hline James and Sargent (Department of Finance) & Canada & $0.30 \%$ & $1.10 \%$ \\
\hline Jonug and Kroger & Europe & & $-1.60 \%$ \\
\hline Kennedy, Thompson \& Vujanovic (Treasury Department) & Australia & & $6 \%$ \\
\hline
\end{tabular}

The research and studies reviewed in this section lead to several observations:

- The primary economic impact areas resulting from pandemic influenza are an increase in absenteeism, changes in consumer behavior, and long-term effects of mortality;

- Mounting evidence suggests that consumers do alter their behavior in response to the potential for illness.

\section{Pre-Modeling to Prepare the Forecasting Model}

\subsection{Description of the Regional Economics Models, Inc.}

Economic impact estimates were generated using the Regional Economics Models, Inc. (REMI) PI $+^{3}$ macroeconomic model, a dynamic model that can generate economic estimates over a long-term future period-ten years in the case of the H5N1 study and forty years in the case of the H1N1 study. REMI is a dynamic, input-output model of the entire United States which can simulate a wide variety of economic and demographic effects, providing results on an annual basis. ${ }^{4}$ The particular REMI model used contains 51 regions (one for each state and the District of Columbia) and 70 economic sectors, and can estimate impacts through the year 2050.

Figure 5-1 illustrates the major categories of REMI economic variables and relationships that capture economic and demographic activity (such as population levels and movements) across the nation, between states, and within states. These relationships are based on annual data collected by the federal government (e.g., input-output accounts that describe the flow of goods to make

${ }^{3}$ Regional Economic Models, Inc. “REMI PI+”, v. 1.0.114, March 24, 2009 build, 51 region, 70 sector model, Amherst, MA.

${ }^{4}$ For a more detailed description of the REMI model, see the resources available at REMI's website (www.remi.com), including: Treyz, George I., Dan S. Rickman, and Gang Shao, 1991, “The REMI Economic-Demographic Forecasting and Simulation Model,” International Regional Science Review, 14(3), pp. 221-253 
commodities in different industries) and on econometric estimation of the parameters defining key relationships between variables within the model (e.g., the price elasticity of consumer demand for a variety of consumer products) using historical data.

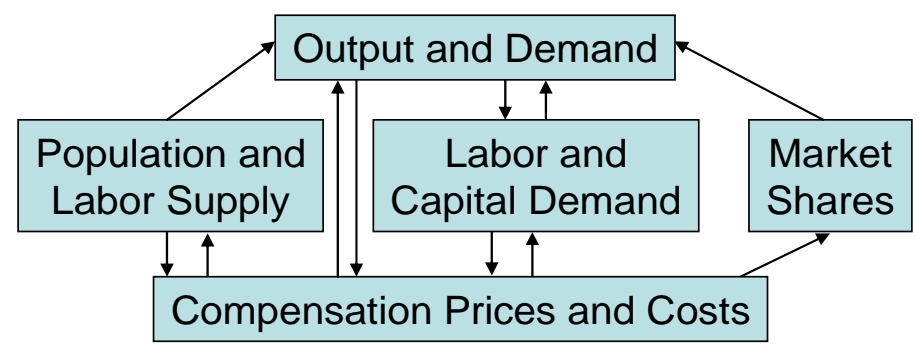

\section{Figure 5-1: Major REMI ${ }^{5}$ Economic Variable Categories and Relationships}

A REMI analysis is carried out in two steps. In the first step the REMI model simulates a baseline forecast of the U.S. economy using hundreds of detailed region and sector variables and relationships within broad categories of variables. Each version of REMI contains a built-in baseline forecast (termed the "standard control") which reflects publicly available macroeconomic forecasts as well as forecasts developed by Regional Economic Models, Inc. The standard control forecast includes estimates of macro-economic variable values reflecting the current economic recession. REMI model users can make additional adjustments to baseline forecasts.

In the second step, changes in this baseline behavior, e.g., caused by pandemic influenza, can be made by specifying exogenous changes in the economic variables for specific regions and forecast years. REMI incorporates those changes into the simulation, and the effects of these exogenous changes are measured by comparing variable values in the baseline forecast within variable values from the simulation that incorporates the exogenous changes. For example, in Figure 5-2 below, the solid line shows the baseline forecast of GDP between 2007 and 2020, while the dashed line shows an alternate forecast due to a hypothetical impact in 2009. The difference between the two lines is the forecast economic impact.

\footnotetext{
${ }^{5}$ REMI is an abbreviation for Regional Economic Models, Inc.
} 


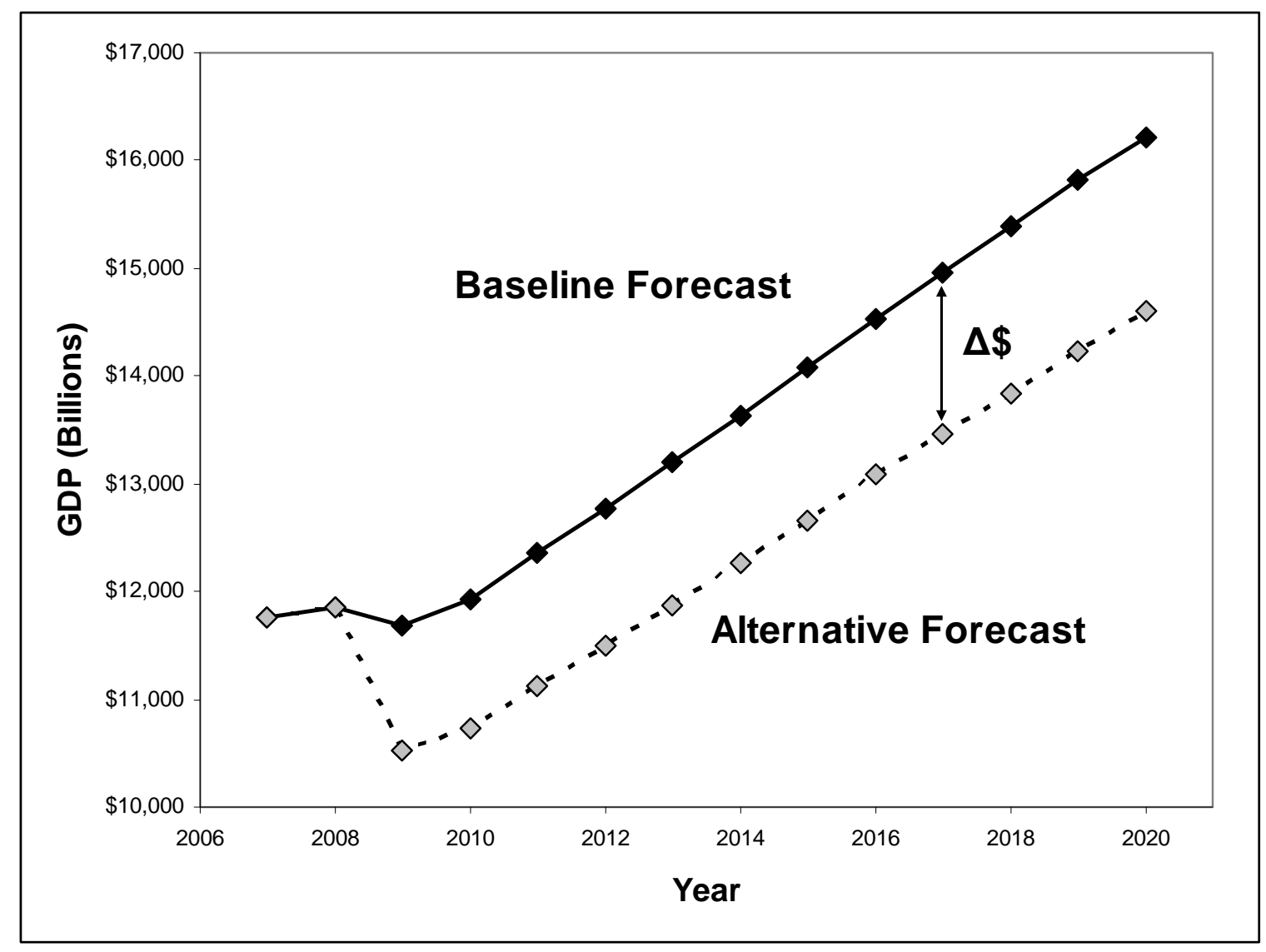

Figure 5-2: Economic Impacts are Measured as Difference between Impact and Baseline Forecasts

As with any macroeconomic model, the REMI model has limitations that bias its estimates of the impacts of climate change. First, it models actual U.S. firms as an aggregation of a large number of firms, thereby aggregating the true relationships between firms and their individual actions within markets. Second, the behavior in REMI is driven by observed, historic data on goods and services and the technologies that make them. Considering the magnitude of technological change that has occurred over the past forty years, it is very difficult for any economic model to forecast the pace and consequences of technological and economic change over the next forty years. Third, significant pre-modeling must be done to convert, e.g., epidemiological impacts, into a form that can be input into the REMI model, and this pre-modeling may have inherent biases. Finally, as mentioned above, there are significant uncertainties regarding the effects of pandemic influenza, and of the direct and indirect effects on the U.S. economy. These and other factors influence confidence in economic forecasts.

\subsection{Increased Absenteeism in the Workplace}

One of the three main factors important to modeling the effects of pandemic influenzaabsenteeism - is a normal feature of business firm production economics. Workers may be absent due to illness, vacation, visits to the doctor or dentist, to care for ill family members, or for many other reasons. Actual plant and industry-level data as accumulated and published by government and other organizations reflect whatever absenteeism was in evidence during the time period covered by 
the data. Seasonal flu and illness occurs virtually every year and any macro-economic model that uses actual data has some level of absenteeism embedded in its economic relationships. It is virtually impossible to measure the output differential between the ideal state in which all workers are present and the actual state in which some of them are absent. We assume, however, that absenteeism in excess of normal levels leads to a further reduction of output-a supply shock over and above the un-measurable supply shock due to normal absenteeism.

The EpiSimS ${ }^{6}$ epidemiological model estimates excess worker absenteeism by week at the level of census blocks for each 6-digit NAICS industry code for the duration of the specified pandemic. This model was run under a separate but collaborative effort conducted at the Los Alamos National Laboratory (LANL). Data were aggregated to 66 two-digit NAICS industry codes for each state to coincide with the most detailed industry and geographic categorization available in our version of the REMI PI+ model. The economists further transformed the absenteeism results by industry by dividing total absenteeism due to the pandemic influenza into a worker productivity component and a "true" absenteeism component represented as a reduction in employment for that state/sector combination. Thus, absenteeism was treated as having two distinguishable effects on the firms/industries experiencing absenteeism: true absenteeism, wherein workers were absent from their jobs, and a reduction of worker productivity due to absenteeism. True absenteeism-the smaller of the two phenomena-was treated as a direct reduction in employment, estimated at onethird of the overall absence-reduction in the workforce. The second effect was treated as a reduction in labor productivity.

Modeling absenteeism at the census block level (subsequently aggregated to the state level) as well as for different industry sectors (using 6-digit NAICS sectors subsequently aggregated to 2-digit industries) means that it is possible that industries in the same geographic area might experience different economic impacts as a result of the pandemic. By extension, different states might be differentially affected as well.

\subsection{Mortality Modeled as Reduced Survival}

Mortality affects both the number of workers (supply shock) and the number of consumers (demand shock). REMI has an embedded, detailed, demographic model that enables the representation of mortality as a reduction in the survival rate of individuals in each state. Economists calculated incremental death rates for each state by forming a ratio of the total number of deceased individuals from all age groups for a state as the numerator, and the total population of the state as the denominator. They then applied the incremental death rate from the pandemic as a reduction of the base case survival rate for that state.

\subsection{Consumption Spending Response}

Literature relevant to the issue of a fear-based response on the part of consumers (demand shock) provides evidence in support of this phenomenon. For this analysis, economists chose particular categories of consumer spending based on the accumulating evidence contained in this literature.

${ }^{6}$ Del Valle, SY, PD Stroud, JP Smith, SM Mniszewski, JM Riese, SJ Sydoriak, DA Kubicek. 2006. EpiSimS: Epidemic Simulation System. Los Alamos Unlimited Release (LAUR) 06-06714. 
This evidence shows that consumers are likely to adjust their spending in response to their increased fear and uncertainty regarding their immediate future circumstances. Due to the current recessionary economic circumstances, data indicates consumers have already somewhat adjusted their spending in response to either reduced incomes or to the threat of reduced incomes in the future. Furthermore, current data also shows that consumer confidence about the economy is declining. Consumers may accordingly curtail their ability to further reduce spending in response to another economic/social shock. Nevertheless, it is likely that further reductions are possible; therefore, economists identified certain categories of consumption that, according to the logic described below, are likely areas in which consumers could cut expenditures further.

Economists made a distinction between delay of expenditures and expenditures unlikely to be recovered upon the return of normal economic circumstances. For example, the likelihood that some consumers will delay purchases of big-ticket items such as durable home appliances, automobiles, and new housing is postulated. Upon the return of normal economic circumstances, consumers are postulated to proceed with such expenditures. In a dynamic analysis the year-on-year changes would wash each other out. In contrast, consumers who avoid taking a vacation this year are unlikely to take two vacations next year to make up for the year they went without one. The same is true of restaurant meals and other types of spending on consumables. We identified similar categories of spending in which reductions in spending this year would likely not be recovered by increased spending in future years.

The healthcare category of consumption spending is very likely to increase due to increased illness. This is reflected in the assumed percentage changes. However, due to the current depressed economic conditions, consumers may try to limit additional spending for medical services. Accordingly, a modest increase in this category of spending is postulated. The small percentage change in spending within each category is consistent with the limited severity of the current H1N1 outbreak. Very different economic circumstances (real property and financial services bubbles) were pertinent to the H5N1 analysis and higher percentage increases were assumed for this case. The national economy was still on a growth trajectory during this time, although, in retrospect, the seeds of the coming recession were being sown.

\section{Pandemic Influenza Simulations}

\subsection{H5N1 (Avian Flu) Scenario Descriptions ${ }^{7}$}

Economists identified six scenarios to define a range of possible responses to the pandemic on the part of public authorities. They are described briefly as:

- Baseline: No intervention; unconstrained pandemic;

- Fear-40: Only strong voluntary self-isolation (beginning on day 57, ramping up to 40 percent on day 63 then ramping back down to zero on day 70), no intervention;

\footnotetext{
${ }^{7}$ More detailed scenario descriptions are available in "National Population, Economic, and Infrastructure Impacts of Pandemic Influenza with Strategic Recommendations,” prepared by National Infrastructure Simulation and Analysis Center, Infrastructure Analysis and Strategy Division, Office of Infrastructure Protection, U. S. Department of Homeland Security, October 2007.
} 
- Community Mitigation Guidance: Unlimited antivirals, strong social distancing, complete school closure for duration of epidemic, no circulating symptomatic people ("liberal leave”), partial quarantine of the families of sick people from day 1, partial reduction in children's activities, and no voluntary isolation;

- Community Mitigation Guidance-Selected Elements: Unlimited antivirals and strong social distancing only;

- Antivirals: Application of stockpile antivirals only;

- Anticipated: stockpile-only antivirals, mild social distancing ${ }^{8}$, limited school closure, weak voluntary isolation, and normal vaccine production and timing.

\subsubsection{Important Scenario Parameters, Assumptions}

Table 6-1 summarizes the key epidemiological parameters that drive workplace absenteeism and mortality for the seven scenarios. The clinical attack rate drives the pandemic's absenteeism and is highly positively correlated to the mortality rate.

Table 6-1: Key Epidemiological Parameters

\begin{tabular}{|l|c|c|}
\hline Scenario Name & $\begin{array}{c}\text { Clinical } \\
\text { Attack Rate }\end{array}$ & $\begin{array}{c}\text { Mortality } \\
\text { Rate }\end{array}$ \\
\hline Baseline & 0.26 & 0.0053 \\
\hline Antiviral & 0.25 & 0.0047 \\
\hline Fear-40 & 0.21 & 0.0043 \\
\hline CMG-SE $^{9}$ & 0.10 & 0.0055 \\
\hline Anticipated & 0.0092 & 0.000064 \\
\hline CMG & 0.0045 & 0.000027 \\
\hline
\end{tabular}

The level of worldwide concern for the H5N1 influenza led us to conclude that consumers might make significant adjustments to expenditures. Possible adjustments to expenditures would include consumer durables as well as spending on consumables. Accordingly, consumer spending during the year of the pandemic was reduced by 4 percent for vehicles and parts, computers and furniture, other durables, clothing and shoes, transportation, and other services. Medical care expenditures were increased by 4 percent to account for the likely greater spending to care for ill persons.

\subsubsection{Simulation Results}

The estimated national total GDP reduction for each scenario, measured in constant 2000 dollars, is shown in Table 6-2 for year 1 and the accumulated GDP loss for years 1-10 (also shown in constant 2000 undiscounted dollars).

\footnotetext{
${ }^{8}$ The phrase social distancing encompasses a variety of individual behavioral modifications that can reduce disease transmission, including improved hygiene, cough etiquette, handshake avoidance, maintenance of interpersonal space, and mask-wearing.

${ }^{9}$ CMG-SE is an abbreviation for Community Mitigation Guidance-Selected Elements.
} 
Table 6-2: Estimated National Gross Domestic Product Reductions

\begin{tabular}{|c|c|c|}
\hline $\begin{array}{l}\text { Pandemic } \\
\text { Scenario }\end{array}$ & Year 1 & Years 1-10 \\
\hline \multicolumn{3}{|l|}{ Baseline } \\
\hline Level \$Billions & $\$ 120$ to $\$ 350$ & $\$ 810$ to $\$ 1,100$ \\
\hline$\%$ GDP $^{10}$ & $1.1 \%$ to $3.1 \%$ & N/A \\
\hline \multicolumn{3}{|l|}{ Fear-40 } \\
\hline Level \$Billions & $\$ 140$ to $\$ 400$ & $\$ 770$ to $\$ 1,000$ \\
\hline \% GDP & $1.2 \%$ to $3.5 \%$ & N/A \\
\hline \multicolumn{3}{|l|}{ Antiviral } \\
\hline Level \$Billions & $\$ 120$ to $\$ 340$ & $\$ 710$ to $\$ 960$ \\
\hline \% GDP & $1.0 \%$ to $2.9 \%$ & N/A \\
\hline \multicolumn{3}{|l|}{ Anticipated } \\
\hline Level \$Billions & $\$ 140$ to $\$ 400$ & $\$ 430$ to $\$ 580$ \\
\hline \% GDP & $1.2 \%$ to $3.5 \%$ & N/A \\
\hline \multicolumn{3}{|l|}{ CMG-SE $^{11}$} \\
\hline Level \$Billions & $\$ 93$ to $\$ 270$ & $\$ 310$ to $\$ 410$ \\
\hline \% GDP & $0.8 \%$ to $2.3 \%$ & N/A \\
\hline \multicolumn{3}{|l|}{ CMG } \\
\hline Level \$Billions & $\$ 95$ to $\$ 280$ & $\$ 290$ to $\$ 400$ \\
\hline \% GDP & $0.9 \%$ to $2.6 \%$ & N/A \\
\hline
\end{tabular}

\subsubsection{Discussion of Simulation Results}

The range of GDP reductions shown in Table 6-2, and listed for each scenario, reflected variations in the consumer demand response, assumed in this analysis to be a percentage reduction for select goods and services and an increase of healthcare expenditures. The modeled changes in consumer behavior implied a 0.2 percent to 2.2 percent reduction in GDP; this reduction is in line with the 0.5 percent demand shock estimated by others for the 1918 pandemic. In Year 1, the baseline scenario economic impacts were between $\$ 120$ and \$350 billion, or 1.1 percent to 3.1 percent of U.S. GDP, depending upon assumptions about consumer demand. The Community Mitigation GuidanceSelected Elements had the lowest economic impacts for Year 1 due to a combination of low absenteeism and deaths, and Community Mitigation Guidance had the lowest economic impacts for Years 1-10 because of fewer deaths. This reduction over the baseline was due to fewer ill people, which reduced workplace absenteeism, and fewer deaths, which reduced losses to U.S. economic capacity. The total short-term economic impacts, which were driven by the uncertainty in demand shock, differed only slightly between scenarios.

Analysis of results for economic sectors, shown in Figure 6-1, indicate that the economic subsectors sustaining the largest GDP reductions are manufacturing, which would lose an estimated \$95 billion in output, followed by the finance and insurance sector, with a $\$ 40$ billion loss, and retail trade, with

\footnotetext{
${ }^{10}$ GDP is an abbreviation for Gross Domestic Product.

${ }^{11}$ CMG-SE is an abbreviation for Community Mitigation Guidance-Selected Elements.
} 
a $\$ 32$ billion loss. These impacts can be attributed to a combination of the demand, supply, and population shocks. Each of these factors has a different impact across economic subsectors. Demand shock has a strong impact in a number of the manufacturing subsectors that produce final goods for consumers. Other subsectors that provide intermediate goods and services to the manufacturing subsector also lose sales and GDP. Reduced manufacturing wages reduce purchases across consumer spending categories. The supply shock is distributed across subsectors based on employment levels. The effects of absenteeism-based supply shock are greatest in manufacturing, followed by finance and insurance, retail, wholesale, real estate, and construction. The population shock is likewise strongest in manufacturing, followed by real estate, then finance and insurance, reflecting the combined effects of large numbers of employees in these three subsectors.

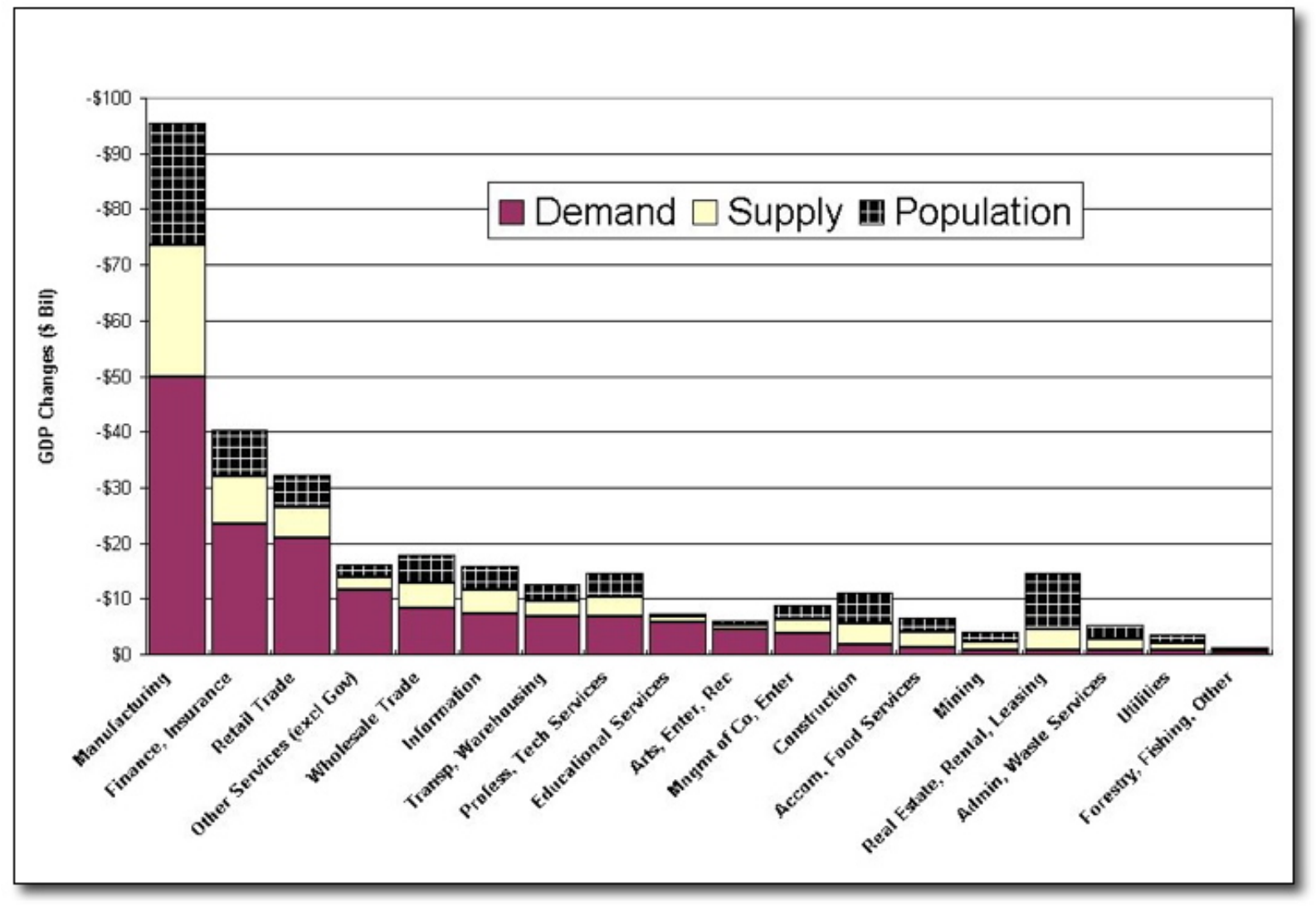

Figure 6-1: Average Gross Domestic Product Losses, by Type of Shock and Industry: Year 1, Baseline Scenario

Year 1 GDP reductions vary regionally across the country largely due to differing state-to-state industrial sector concentrations and population densities as shown in Figure 6-2. California, Michigan, Indiana, New York, and some New England states bear the brunt of the percentage GDP reductions. For example, large impacts in California and Michigan are likely due to both states having significant manufacturing subsectors and experiencing reductions in consumer spending. Other highly populated states, such as Florida, experience lower-than-average impacts likely due to lower-than-average manufacturing activity. 


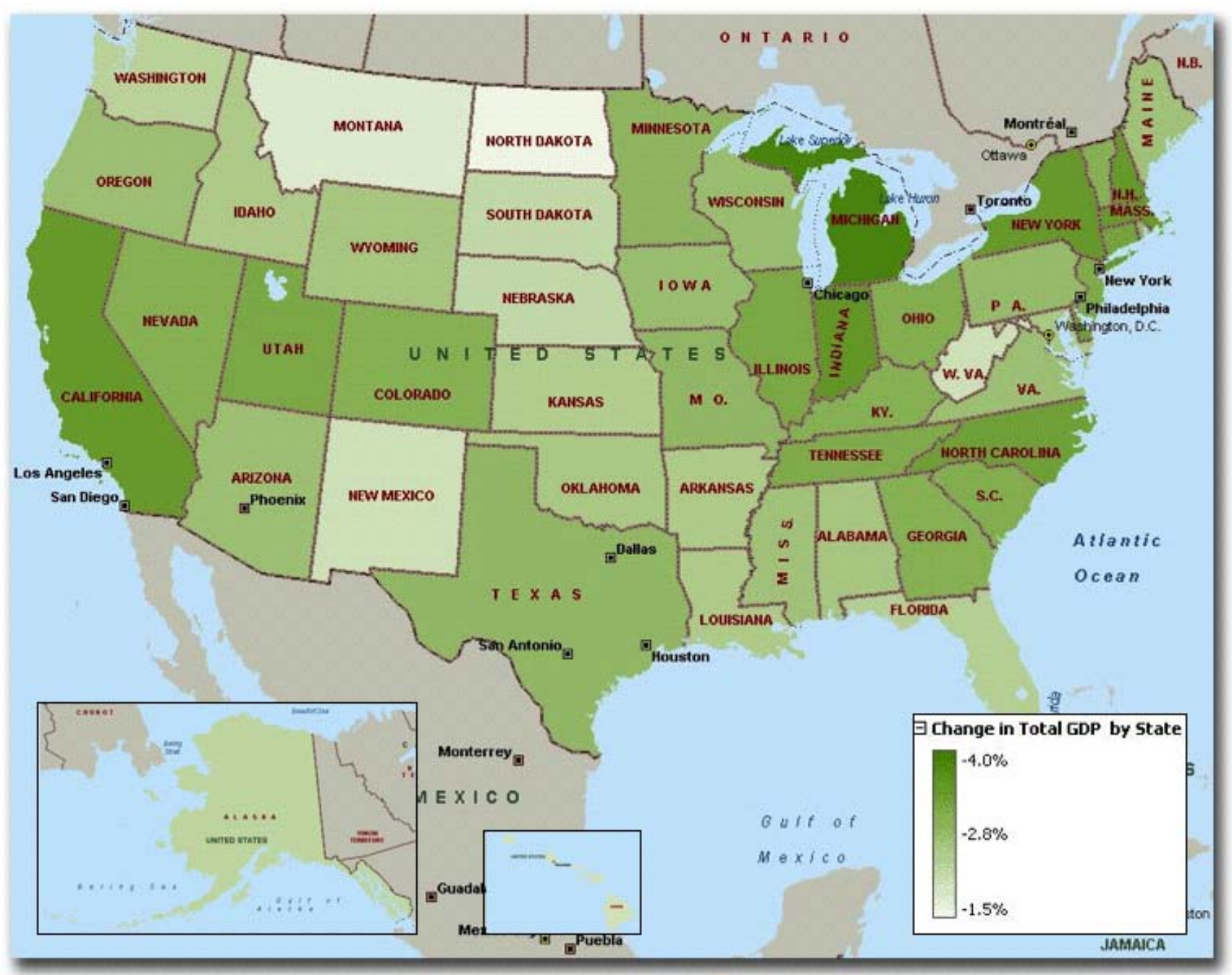

Figure 6-2: Percent Changes in Gross Domestic Product by State: Baseline Scenario, Year 1

Simulation results suggest latitude for policy makers' choices; however, a more complete economic policy analysis would require additional effort to tally the cost of implementation and enforcement of the suite of possible interventions. ${ }^{12}$ In terms of first year costs alone, all of the scenarios can be said to be roughly equivalent. ${ }^{13}$ With Year One baseline costs at a little over $\$ 100$ billion, costly interventions may not be economically efficient since the most that could be saved is on the order of $\$ 30$ billion in point-estimated value. However, taking a longer-term perspective, the 10-year cost of mortality associated with baseline non-intervention has the highest GDP reduction range.

\footnotetext{
${ }^{12}$ Implementation and enforcement costs would be incurred in year 1 dollars. Subsequent reductions (of GDP reductions; i.e., "savings") would need to be discounted in the out years in order to achieve a valid comparison.

${ }^{13}$ The REMI model is deterministic, so does not support probabilistic analysis. However, informal introduction of statistical variability suggests that GDP reduction point estimates shown in the year 1 column may not be significantly different from one another (for each exogenous consumer spending assumption).
} 
Although the CMG (Community Mitigation Guidance) and CMG-SE (Community Mitigation Guidance-Selected Elements) mitigation plans were the least costly in the long-run, the results of the anticipated scenario indicated that the way in which measures are ultimately implemented, the compliance rate, and behavioral reactions will all play important roles in the long-term economic impacts. If public health intervention techniques are not as effective as represented in the scenarios, the costs will be greater. The anticipated scenario is representative of what may be expected under more realistic conditions because it constrains treatment resources and limits intervention efficacy such that there is a workforce impact. The intervention strategy of the anticipated scenario has a short-term economic impact similar to that of the less-effective mitigation strategies, although it has a low long-term economic impact similar to that of the CMG and CMG-SE scenarios.

\subsection{H1N1 (Swine Flu) Scenarios ${ }^{14}$}

Three scenarios were developed and simulated for the economic analysis of the H1N1flu. They are described below:

- Mutated 2009 H1N1: Seasonal flu plus mutated H1N1 strains co-circulating; no interventions;

- $\quad$ Novel 2009 H1N1 + Seasonal flu: Background plus 1⁄2 (H1N1 + Seasonal); no interventions

- Isolation: Background + 3.2 percent absenteeism for all states and industry sectors; no interventions.

\subsubsection{Important Scenario Parameters, Assumptions}

The supply shock for the H1N1scenarios have the same origin as for the H5N1 scenarios; namely, absenteeism in the workplace due to illness and mortality that follows from illness for some individuals. The Seasonal influenza has an attack rate averaging approximately 9.32 percent and annual mortality ranging between 36,000 and 41,000. The novel $2009 \mathrm{H} 1 \mathrm{~N} 1$ has an attack rate of 1525 percent and a case mortality rate of 0.46 percent while the mutated H1N1 has an attack rate in the range of 25-35 percent and a case mortality rate of 1 percent. The mutated strain is significantly more virulent. Absenteeism and mortality estimates are generated through the EpiSimS model except in the case of the Isolation scenario in which a country-wide and industry-wide absenteeism rate is postulated.

For the consumer spending response a distinction is made between delay of expenditures and expenditures that, once postponed or cancelled, are unlikely to be recovered later upon the return of normal economic circumstances. For example, it is likely that some consumers will delay purchases of big-ticket items such as durable home appliances, automobiles, and new housing. However, upon the return of normal economic circumstances, consumers are likely to proceed with such expenditures. In a dynamic analysis such as this study, the year-on-year changes would wash each other out. In contrast to the H5N1 analysis, for this study no exogenous changes are made to expenditures on durable goods.

\footnotetext{
${ }^{14}$ More detailed description of the scenarios is available in "National Population and Economic Impacts of 2009 Influenza A (H1N1), prepared for the Department of Homeland Security Office of Health Affairs, Homeland Infrastructure Threat Risk Analysis Center, Risk Development and Modeling Branch, National Infrastructure Simulation and Analysis Center. September 2009.
} 
As in the H5N1 analysis, consumers are postulated to reduce spending on nondurables in some H1N1 scenarios. For example, consumers who avoid taking a vacation this year are unlikely to take two vacations next year to make up for the year they went without. The same is true of restaurant meals and other types of spending on consumables. This approach was applied to similar categories of spending in which reductions this year would likely not be recovered by increased spending in future years. Generally the spending categories related to food, travel, entertainment, and accommodation were reduced by one percent for the Mutated H1N1 and Novel H1N1 scenarios. For the Isolation scenario the reductions were 4 percent. The healthcare category of consumption spending is assumed to increase by 4 percent for the Mutated H1N1 and Novel H1N1 scenarios; for the Isolation scenario no change is assumed.

\subsubsection{Simulation Results}

Table 6-3: shows the results of the simulations for the H1N1 pandemic influenza scenarios. These results are also shown in terms of constant dollar GDP reductions but these results are denominated in year 2000 constant dollars for two periods-year 1 of the pandemic and years 2-25 following the pandemic.

Table 6-3: Estimated National Gross Domestic Product Reductions

\begin{tabular}{|c|c|c|}
\hline Pandemic Scenario & $\begin{array}{c}\text { GDP } \\
\text { Reduction } \\
\text { Year 1 }\end{array}$ & $\begin{array}{c}\text { GDP } \\
\text { Reduction } \\
\text { Years 2-25 }\end{array}$ \\
\hline Mutated 2009 H1N1 + Seasonal & & \\
\hline Level \$Billions & $\$ 42$ & $\$ 237$ \\
\hline \% GDP & $0.36 \%$ & N/A \\
\hline 2009 H1N1 + Seasonal & & \\
\hline Level \$Billions & $\$ 25$ & $\$ 53$ \\
\hline \% GDP & $0.21 \%$ & N/A \\
\hline Isolation + Seasonal & & \\
\hline Level \$Billions & $\$ 290$ & N/A \\
\hline \% GDP & $1.0 \%$ to $2.9 \%$ & N/A \\
\hline
\end{tabular}

Table 6-3: displays the results for the Mutated 2009 H1N1 scenarios and Isolation scenario in terms of 2000 constant dollar GDP reduction and GDP percentage reduction. The results are reported for two time periods: the first year of the pandemic and the years 2-25.

\subsubsection{Discussion of Simulation Results}

The Mutated 2009 H1N1 scenario reduction in GDP for the pandemic year reaches $\$ 42$ billion, a 0.36 percent reduction from its control value. The World Bank criteria would rank the Mutated 2009 H1N1 scenario as a mild pandemic from an economic perspective ${ }^{16}$ For the Isolation scenario, the

\footnotetext{
${ }^{15}$ GDP is an abbreviation for Gross Domestic Product

${ }^{16}$ Timmer, H., A. Burns, and D. van der Mensbrugghe. June 24, 2009. Evaluating the Economic Consequences of Avian Influenza, Global Development Finance (2008): 1-5. World Bank Development Economics Directorate, siteresources.worldbank.org/INTGDF2009/.../gdf_combined_web.pdf.
} 
GDP reduction is substantially greater at $\$ 290$ billion, a 2.5 percent reduction in GDP for the first year of the pandemic, ranking this scenario as a moderate pandemic according to the World Bank criteria. The co-circulating 2009 H1N1 with Seasonal Influenza scenario results show the ameliorating effect of the vaccine; GDP reduction declines from $\$ 42$ billion to $\$ 25$ billion.

Much of the GDP reduction in the Isolation scenario (when compared with the Mutated 2009 H1N1 scenario) results from the efforts of people to self-isolate and not from the direct effects of the disease on individuals through morbidity and mortality. The effort to reduce disease spread through isolation has a significant effect through the resulting (assumed) reduction in consumer expenditures. If effectively implemented (as assumed here), isolation buys a very important reduction in mortality which, as indicated by the economic impact of the mortality in Mutated 2009 H1N1 scenario, can be very costly.

The component economic shocks-excess absenteeism (supply), consumption changes (demand), and mortality (a reduction of population) - have different impacts across economic sectors as shown in Figure 6-3. In terms of total GDP, the Manufacturing Sector has the greatest loss, almost $\$ 6$ billion in GDP, followed by real estate rental and leasing, finance and insurance, and retail trade at almost $\$ 5$ billion in each sector. Most of the manufacturing and finance and insurance GDP losses are attributed to the supply shock (output reductions due to worker absenteeism). The effects of the absenteeism-based supply shock are greatest in manufacturing, followed by finance and insurance, retail trade, and real estate rental and leasing. The consumer spending (demand) shock dominates retail trade and accommodation and food services, as expected. GDP reductions in the demand shock also dominate GDP reductions in the arts, entertainment, and recreation industry subsector.

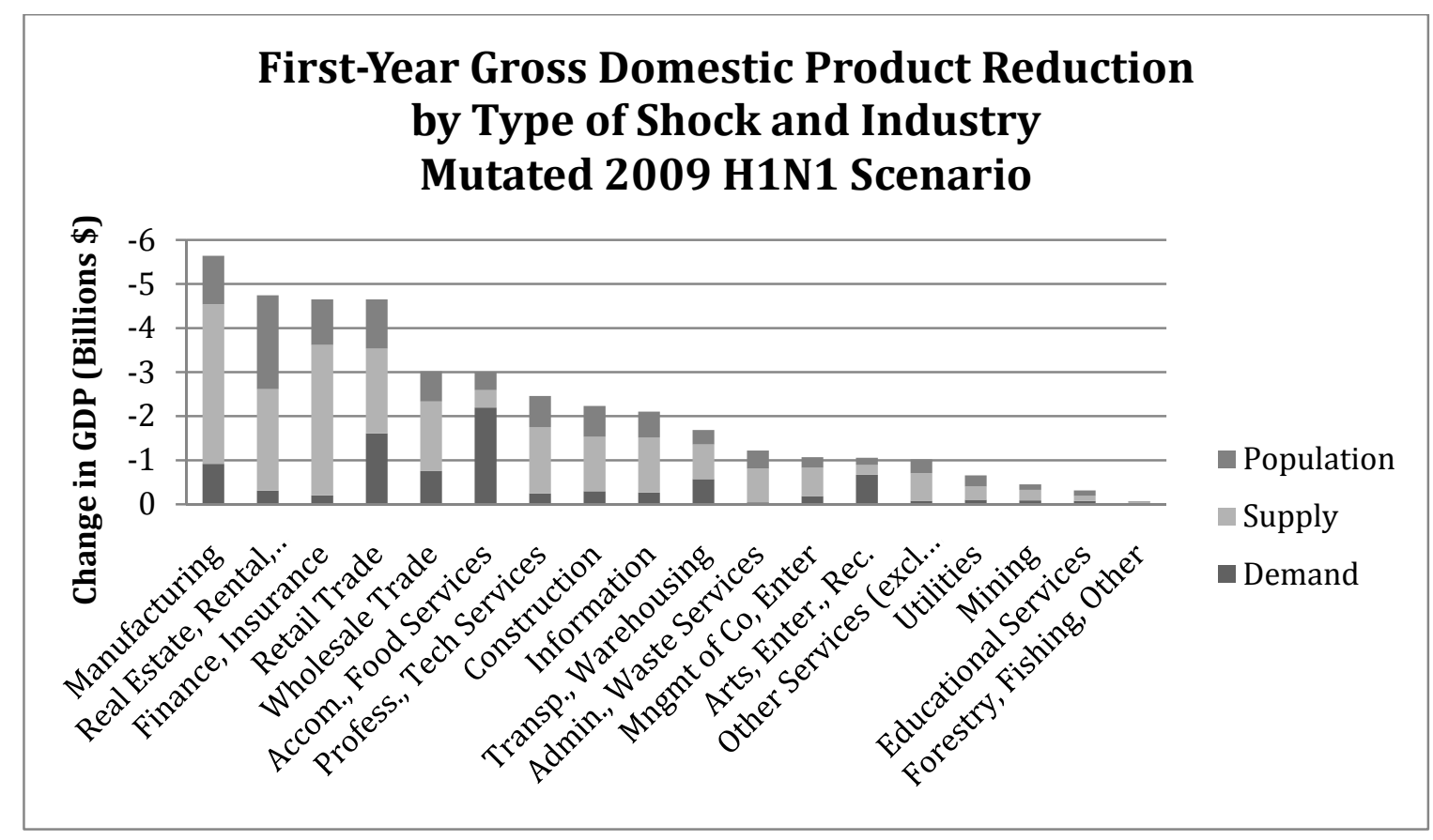

Figure 6-3: Factor Analysis for Selected Industry Sectors

Among the three types of shock (supply, demand, and population), the supply shock has the strongest impact across most of the sectors, as seen in Figure 6-3. For the Manufacturing Sector, 
demand is reduced in subsectors that produce final goods for consumers. The population effect is likewise strongest in the real estate rental and leasing and manufacturing subsectors, followed by retail trade, reflecting the combined effects of large numbers of employees and labor intensity in these subsectors.

The co-circulating 2009 H1N1 + seasonal influenza scenario industry sector chart, shown in Figure 6-4Figure 6-3, presents some interesting findings when comparing the sources of the economic shocks. Consumer spending reduction, a demand side shock, is the dominant factor in the accommodation and food services GDP reduction. In contrast, the finance and insurance GDP reduction is dominated by worker absences, the supply side phenomena. In some subsectors, for example, retail trade, the cause of the total GDP reduction is shared approximately equally between the supply and demand shocks.

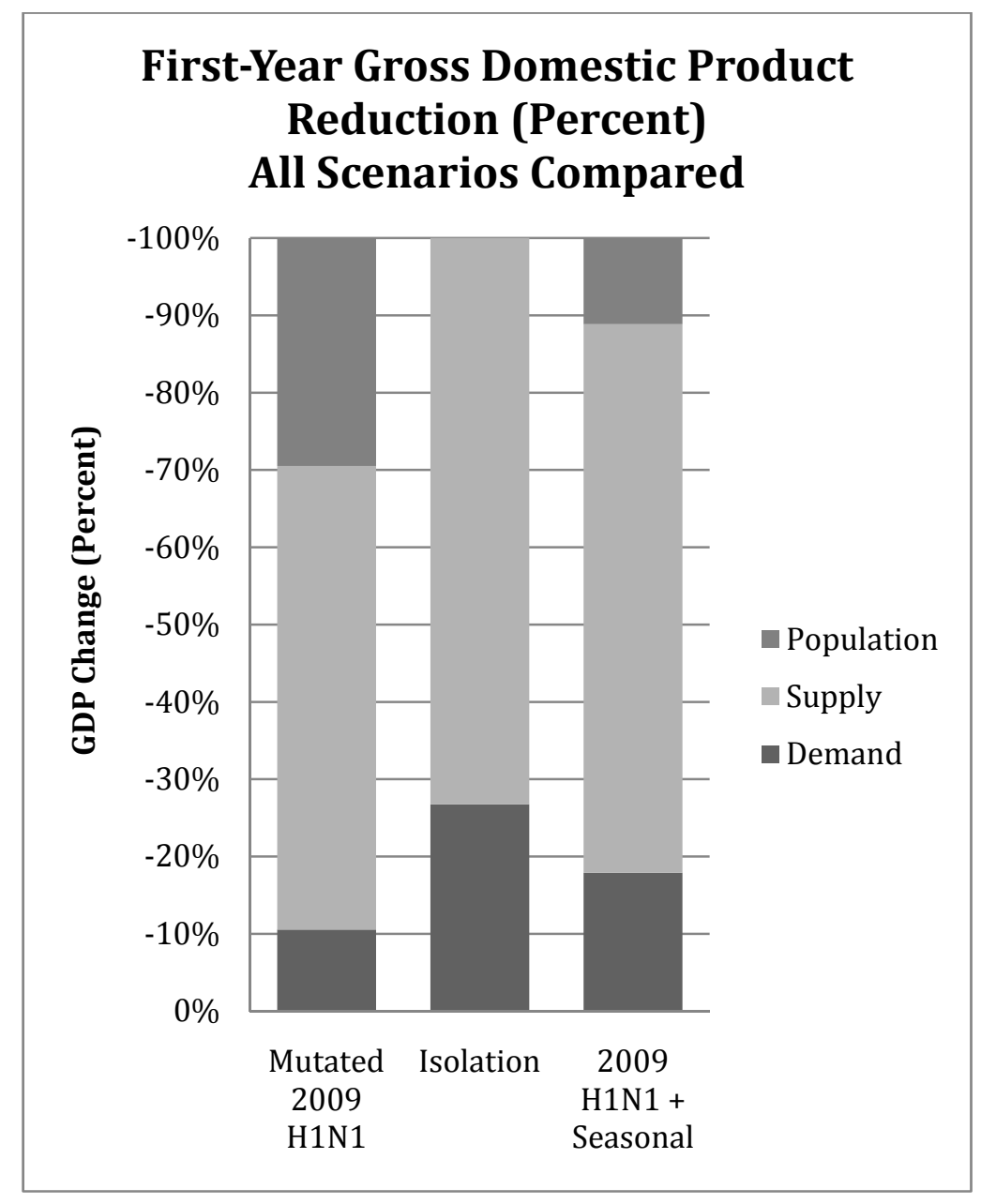

Figure 6-4: Percentage Gross Domestic Product Reductions for Three Scenarios

Figure 6-4 presents an analysis of the first-year relative effect of each of the three component shocks across the three scenarios that were examined in this study. The chart shows the percent change in GDP for each scenario respectively using the REMI standard control as a base from which to compare. The Isolation scenario shown in the middle bar is the only scenario with essentially no 
mortality. However, absenteeism, due to the self-isolation factor, is very high in this scenario and contributes about 65\% to the total GDP reduction that Table 6-3: shows to be $\$ 290$ billion in the first year. Voluntary or enforced isolation therefore turns out to be a very expensive option. The Mutated 2009 H1N1 has more than double the mortality of the 2009 H1N1 plus seasonal flu, highlighting the severe virulence of the mutated strain. The demand effect is the smallest relative contributor to GDP reductions in the Mutated scenario.

Extending this discussion beyond first-year effects, it is apparent from Table 6-3: that when out-year economic impacts are included, a somewhat different picture emerges. We see that for the Mutated 2009 H1N1 scenario the impacts in the out-years total $\$ 237$ billion, that, when added to the \$42 billion first-year impacts rivals the large first-year impact of the Isolation scenario. The factor causing this accumulated $\$ 237$ billion GDP reduction is mortality. While it was not specifically extended out beyond 25 years, the mortality loss is one from which the economy never recovers. In principle the same observations apply to the H1N1 Plus Seasonal scenario, though the total impacts of this scenario are lower than the other two.

\section{Concluding Observations}

Both sets of economic simulations conducted indicate that the durable economic feature of influenza pandemic is the mortality it causes, if any. The short-term costs are comprised primarily of consumer spending and output reductions due to workplace absences. While this short-term dip in GDP is notable, much of the reduction is recoverable in subsequent periods by normal response to and recovery from the business cycle. Accordingly it is important for public health authorities to identify policy actions that mitigate the spread of the disease in the short-term but that do not result in substantial social distancing. This is likely to be a very difficult balancing act in the short-term. It seems to highlight the importance of timely vaccination programs.

\section{References}

Aledort, Julia E., Nicole Lurie, Jeffrey Wasserman, and Samuel A. Bozzette, August 15, 2007. NonPharmaceutical Public Health Interventions for Pandemic Influenza: An Evaluation of the Evidence Base, BMC Public Health. http://www.biomedcentral.com/1471-2458/7/208.

Bloom, E., V. de Wit, and M.J. Carangal-San Jose, 2005. Potential Economic Impact of an Avian Flu Pandemic on Asia, Economics and Research Department Policy Brief, Asian Development Bank, http://www.adb.org/Documents/EDRC/Policy_Briefs/PB042.pdf.

Congressional Budget Office Assessment, Dec. 2005, revised July 2006. A Potential Influenza Pandemic: Possible Macroeconomic Effects and Policy Issues, Congressional Budget Office, www.cbo.gov/ftpdocs/69xx/doc6946/12-08-BirdFlu.pdf.

Cutler, David, Angus Deaton, and Adriana Lleras-Muney, Summer 2006. The Determinants of Mortality, Journal of Economic Perspectives 20/3: 97-120.

Del Valle, S.Y., P.D. Stroud, J.P. Smith, S.M. Mniszewski, J.M. Riese, S.J. Sydoriak, and D.A. Kubicek, 2006. EpiSimS: Epidemic Simulation System. Los Alamos Unlimited Release (LAUR) 06-06714. 
Douglas, J., K. Szeto, and B. Buckle, March 2006. Impacts of a Potential Influenza Pandemic on New Zealand's Macroeconomy, New Zealand Treasury Policy Perspectives Paper, The Treasury, www.treasury.govt.nz/workingpapers/2006/pp06-03.asp.

German, Timothy C., Kai Kadau, Ira M Longini, Jr., and Catherine A. Macken, April 11, 2006. Mitigation Strategies for Pandemic Influenza in the United States. Proceedings of the National Academy of Sciences, U. S. A., http://www.ncbi.nlm.nih.gov/pmc/articles/PMC1458676/?tool=pubmed

Infrastructure Analysis and Strategy Division, Office of Infrastructure Protection, U. S. Department of Homeland Security, October 2007. National Population, Economic, and Infrastructure Impacts of Pandemic Influenza with Strategic Recommendations, National Infrastructure Simulation and Analysis Center.

James, Steven and Timothy Sargent, June 9, 2006. The Economic Impact of an Influenza Pandemic, Economic Analysis and Forecasting Division, Department of Finance, Government of Canada, https://www.fsscc.org/fsscc/influenza/economic_impact.pdf.

Jonung, Lars and Werner Röger, June 2006. The Macroeconomic Effects of a Pandemic in Europe A Model Based Assessment, European Commission Directorate-General for Economic and Financial Affairs, Economic Papers, (old address: www.europa.eu.int/comm/economy_finance.) New address: http://ec.europa.eu/economy_finance/publications/publication_summary716_en.htm.

Kennedy, S., Jim Thomson, and Peter Vujanovic, February 2006. A Primer on the Macroeconomic Effects of an Influenza Pandemic, Australian Government, The Treasury, www.treasury.gov.au/contentitem.asp?NavId=\&ContentID=1069.

Lee, Jong-Wha and Warwick McKibbin, August 2006. Globalization and Disease: The Case of SARS,” Australian National University, Economics RSPAS, Working Paper No. 2003/16.

Lee, Vernon J., Mei Yin Tok, Vincent T. Chow, Kai Hong Phua, Eng Eong Ooi, Paul A. Tambyah, and Mark I. Chen, September 2009. Economic Analysis of Pandemic Influenza Vaccination Strategies in Singapore. PloS ONE, 4/9: e7108, www.plosone.org/.../info:doi percent2F10.1371 percent2Fjournal.pone.0007108.

Lempel, H., Ross A. Hammond, and Joshua M. Epstein. September 30, 2009. Economic Cost and Health Care Workforce Effects of School closures in the U.S. Center on Social and Economic Dynamics, Working Paper No. 55, The Brookings Institution.

McKibbin, W. and Alexandra Sidorenko, February 2006. Global Macroeconomic Consequences of Pandemic Influenza, Washington, D.C. Brookings Institution, Lowy Institution for International Policy, www.lowyinstitute.org/Publication.asp?pid=345.

Regional Economic Models, Inc. March 24, 2009. REMI PI+. 1.0.114. Build, 51 regions, 70 Sector Model, Amherst, MA.

Sadique, M. Z., E. J. Adams, and W. J. Edmunds, 2008. Estimating the Costs of School closure for Mitigating an Influenza Pandemic, BMC Public Health, 8:135, http://www.biodedcentral.com/1471-2458/8/135.

SARS, Australian National University, Economics RSPAS, Working Paper No. 2003/16. http://dspace.anu.edu.au/handle/1885/41232. 
Szues, Thomas D., Christian Ruef, Daniela Muller, E. Sokolovic, Iris Beeler, and Wolfgang Ostermayer, August 2001. The Economic Impact of Influenza in a University Hospital Setting, Infection Control and Hospital Epidemiology, 22/8: 272-274.

Siu, Alan and Y.C. Richard Wong, April 2004. Economic Impact of SARS: The Case of Hong Kong, University of Hong Kong, School of Economics and Finance.

Treyz, George I., Dan S. Rickman, and Gang Shao, 1991. The REMI Economic-Demographic Forecasting and Simulation Model, International Regional Science Review, 14/3: 221-253.

Timmer, H., A. Burns, and D. van der Mensbrugghe, June 24, 2009. Evaluating the Economic Consequences of Avian Influenza, Global Development Finance (2008): 1-5. World Bank Development Economics Directorate, siteresources.worldbank.org/INTGDF2009/.../gdf_combined_web.pdf. 


\section{Distribution}

1 MS 0127 Drake Warren, 12142 (electronic copy)

1 MS 0127 Tommy Woodall, 12140 (electronic copy)

1 MS 1137 Shirley Starks, 6326 (electronic copy)

1 MS 1138 Theresa Brown, 6321 (electronic copy)

1 MS 1138 Pablo Garcia, 6320 (electronic copy)

1 MS 1138 Dan Horschel, 6322 (electronic copy)

1 MS 1138 Steve Kleban, 6326 (electronic copy)

1 MS1138 Verne Loose, 6321 (electronic copy)

1 MS 1138 Lillian Snyder, 6321 (electronic copy) 

This page is intentionally left blank. 


\section{Sandia National Laboratories}

